\title{
The exploitation of low-head hydropower by pressure interchange with air, using siphons
}

\author{
M J French and M B Widden* \\ Engineering Department, Faculty of Applied Sciences, Lancaster University, UK
}

\begin{abstract}
The paper describes and analyses a hydropower system based on siphons in which the pressure of low-head water is converted into air pressure. The analysis suggests that, with careful design of the flow passages to minimize losses, air-pumping efficiencies of 70 per cent or more should be achievable; the overall efficiency of the hydropower system should be better than 60 per cent. Although such values of efficiency are lower than usually found in hydro plant, the economics of the system are likely to be attractive owing to the low capital cost of the system compared with conventional water turbine systems. It is shown that a siphon plant is suitable, in single-stage form, for heads up to about $1.7 \mathrm{~m}$. For higher heads the system can be used in two or more stages.
\end{abstract}

Keywords: hydroelectric, hydropower, low-head, micro-hydro, pneumatic conversion, renewable energy

\section{NOTATION}

$B \quad$ buoyancy head (defined in the text)

$d \quad$ depth of datum level below downstream water surface

$g \quad$ acceleration due to gravity

$H \quad$ available head of water

$K \quad$ overall loss coefficient

$L \quad$ local loss coefficient

$p \quad$ absolute pressure

$p_{0} \quad$ atmospheric pressure

$P \quad$ power per unit area of pipe cross-section

$r \quad$ pressure ratio $=p_{\mathrm{C}} p_{\mathrm{A}}$

$s \quad$ slip ratio (see the next item $s v$ )

sv drift velocity of bubbles upwards relative to water velocity of water

volumetric ratio of air to water in an element height above datum

void fraction (ratio of the air volume to the total volume of an element)

efficiency

density of water

mean density of aerated water
The MS was received on 25 February 2000 and was accepted after revision for publication on 29 September 2000.

*Corresponding author: Engineering Department, Faculty of Applied Sciences, Lancaster University, Lancaster LA1 4YR, UK.

\section{Subscripts}

$\begin{array}{ll}\text { A } & \text { condition at aerator } \\ \text { C } & \text { condition at datum level }\end{array}$

\section{INTRODUCTION}

The global resource of hydropower that is technically capable of being harnessed is estimated to be in the region of $15000 \mathrm{TW}$ h/year. However, about half of this, i.e. 6000-9000 TW h/year, is considered to be uneconomic to exploit at present [1]. A major factor is that much of this energy is available only at low heads. Although water turbines are available to convert the power from low-head water into electricity or other forms, the high capital cost of the installation per unit output often makes such plant uneconomic.

Attention has been drawn to the advantages of converting the energy of water into air pressure energy, in the context of sea waves [2]; at a given pressure drop, the characteristic velocity of the fluid is inversely proportional to the square root of the density; therefore for air it is about 29 times that for water. Conversion of a water head into air pressure allows the use of much smaller and cheaper machines, which do not have to be buried in large structures below water level.

Proposals for interchanging pressure between water and air have been put forward based upon alternating 
displacement mechanisms $[3,4]$ but these suffer from the disadvantages of large size and cyclic operation. A steady flow system, proposed in connection with the proposals for a tidal barrage hydropower system for the Severn Estuary, was based on a known and proven invention, the hydraulic compressor, used a century ago in North America to provide compressed air for mining operations and still in use in some places [5-8]. In this type of compressor, a stream flowing through an inverted siphon entrains air in the downward leg, which is released in a stilling chamber or sump at the bottom at a pressure of a few atmospheres. The deaerated stream then rises through the upward leg of the siphon and resumes its original course to the sea.

Recently, the hydraulic compressor has been proposed for use as a compressor in a gas turbine cycle $[\mathbf{9}, \mathbf{1 0}]$. Because the water has much greater heat capacity than the air and the two fluids are in intimate contact, the compression is very nearly isothermal and so requires less work than a conventional compressor, which is almost adiabatic.

At low-head sites, such as the many weirs already in existence on rivers, it would be costly to excavate the deep stilling chambers that are an essential part of a hydraulic compressor system. The siphon system which is examined in this paper is constructed entirely above ground and is relatively inexpensive.

A siphon converter from water to air pressure was built in the early 1990s at Borrowash on the River Derwent, UK. The device differed significantly from that described here, and its performance was disappointing. Only a brief analysis has been published [11].

The models developed by Rice [7], Berghmans and Ahrens [8] and Bidini et al. [10] include almost every loss and pressure change that occurs, however small. In this paper a different approach is taken; in order to keep the analysis simple, some terms are lumped together and very small terms are omitted, with negligible effect on the results.

\section{BASIS OF THE SYSTEM}

The siphon system which is the subject of this paper can be thought of as an inversion of the hydraulic compressor. A siphon is used to connect the upper and lower reaches of a river, the difference in levels being the available head $H$ (Fig. 1). An aerator A, fitted near the top of the

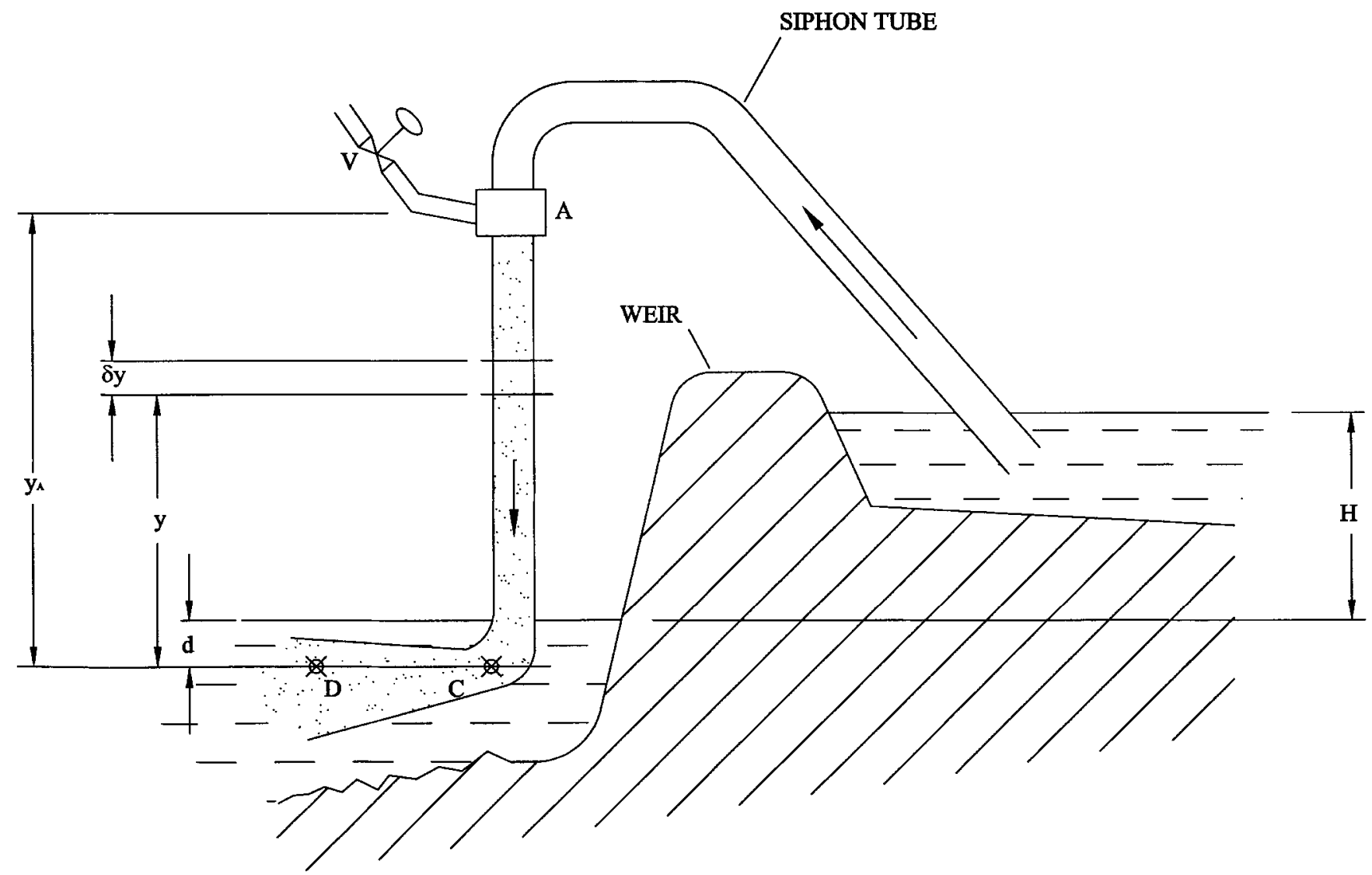

Fig. 1 Schematic diagram of the siphon system 
downward leg of the siphon, is connected to a valve $\mathrm{V}$ which opens to the atmosphere.

With valve $\mathrm{V}$ closed, the water will flow through the siphon from the upper to the lower reach at a velocity such that the loss of head at the inlet, in friction and at the exit is equal to the head $H$. The pressure in the top of the siphon will be substantially below atmospheric. If valve $\mathrm{V}$ is opened slightly, air will be drawn in through the aerator and entrained in the water as small bubbles which are carried downwards to the lower reach. The mean density in the downward leg is reduced by the presence of the bubbles; consequently the driving head, and the velocity of the water, will be reduced. The term 'buoyancy head' $B$ has been used in this paper to denote the reduction in head due to the buoyancy of the bubbles. If the amount of air admitted is gradually increased, the water velocity will fall and the siphon will eventually break. However, at a lower flowrate of air the siphon will run steadily, drawing in air at a pressure slightly above that in the siphon (the process of aeration itself involves a slight loss of head). The siphon works as an air pump, drawing air through the valve. If the valve is replaced with an air turbine, power can be generated. (In practice, the air flow to a number of siphons is likely to be used to power a single turbine.)

A slip loss arises from the upward drift of the bubbles through the water. The relative velocity at which a bubble rises depends on its size, on the concentration of the bubbles and on the effects of containing walls. The rate of rise in unconfined water of a single bubble of diameter between 2 and $20 \mathrm{~mm}$ is less than $0.3 \mathrm{~m} / \mathrm{s}$; for clouds of bubbles influenced by containing walls, the velocity is likely to be reduced $[\mathbf{1 2}, \mathbf{1 3}$ ]. Experiments by Rice [7] showed that the velocity with which a cloud of bubbles in a vertical duct rises relative to water is approximately $0.24 \mathrm{~m} / \mathrm{s}$. The slip $s$ exactly parallels slip in propellers and induction motors and introduces a fractional loss of efficiency in the same way, but, as in propellers and induction motors, there is no work transfer and hence no power without slip.

The void fraction $\alpha$ (the fraction of the total volume that can be occupied by air) is subject to a limit if the flow is to remain in the bubbly regime, i.e. a suspension of many discrete bubbles in a continuous liquid. Wallis [12] quoted experiments which show that for values of the void fraction greater than $\alpha=0.3$ the character of the flow changes from bubbly flow to a new pattern containing very large bubbles which almost fill the duct and will break the siphon.

Calculations based on these values, as set out below, suggest that the conversion of water to air pressure energy can be achieved at 70 per cent efficiency or better. (There is an additional loss because the expansion in the turbine is not isothermal.) If energy cost is the main criterion rather than efficiency in a thermodynamic sense, it may be decided to move away from the optimum efficiency point towards a greater power output.

\section{ANALYSIS}

In this straightforward treatment it is assumed that the compression of the air is isothermal as it descends from A to $C$ (Fig. 1) (see, for example, references [8] and [12]). It is also assumed that the cross-section of the siphon is so shaped that the water flow velocity $v$ is constant throughout the whole length. This assumption is made because sharp variations in $v$ must involve losses; constant $v$ is likely to be close to the practical optimum. Furthermore, while including every small variation makes little difference to the results, it requires numerical integration and makes the analysis less insightful.

\subsection{Pumping section (AC in Fig. 1)}

The friction loss in this straight section is small compared with the gravity term and can be lumped in with the losses upstream and downstream of the pumping section, as is done here (Section 3.2). Consider a horizontal element dy of the descending flow, $y$ being the height above $\mathrm{C}$ (see Fig. 1). Let the ratio of the volume of air in it to the volume of water be $x$. The density of air is only about 0.12 per cent of the density of water at normal ambient pressures and will be still less at the reduced pressure in the siphon. Thus the mean density $\rho_{\mathrm{e}}$ of the element is given, with error less than 0.12 per cent, by

$$
\rho_{\mathrm{e}}=\frac{\rho}{1+x}
$$

Since there is no acceleration, the pressure change over height $\mathrm{d} y$ is given by

$$
\mathrm{d} p=-\rho_{\mathrm{e}} g \mathrm{~d} y
$$

If the drift velocity of the bubbles, $s v$, is constant between points $\mathrm{A}$ and $\mathrm{C}$, then $x$, the volumetric ratio of air to water, will vary with the absolute pressure according to

$$
x=\frac{x_{\mathrm{C}} p_{\mathrm{C}}}{p}
$$

because the air is being compressed isothermally.

(In fact, the drift velocity varies a little with bubble diameter and will change as the bubbles descend and the pressure increases. However, $s v$ is nearly constant for bubble diameters between $1 \mathrm{~mm}$ and $4 \mathrm{~mm}$ [12], which is the likely range of bubble sizes in the siphon. Since the variation in $s v$ is small, it is treated as constant over height AC.)

Combining equations (1) and (2),

$$
\mathrm{d} p=-\frac{1}{1+x} \rho g \mathrm{~d} y
$$

Substituting for $x$ from equation (3) and integrating 
between points $\mathrm{A}$ and $\mathrm{C}$,

$$
\int_{p_{\mathrm{A}}}^{p_{\mathrm{C}}}\left(1+\frac{x_{\mathrm{C}} p_{\mathrm{C}}}{p}\right) \mathrm{d} p=-\int_{y_{\mathrm{A}}}^{0} \rho g \mathrm{~d} y
$$

which gives

$$
\left(p_{\mathrm{C}}-p_{\mathrm{A}}\right)+x_{\mathrm{C}} p_{\mathrm{C}} \ln \left(\frac{p_{\mathrm{C}}}{p_{\mathrm{A}}}\right)=\rho g y_{\mathrm{A}}
$$

Replacing $x_{\mathrm{C}}$ in equation (6) by $x_{\mathrm{A}} p_{\mathrm{A}} / p_{\mathrm{C}}$,

$$
\rho g y_{\mathrm{A}}=\left(p_{\mathrm{C}}-p_{\mathrm{A}}\right)+x_{\mathrm{A}} p_{\mathrm{C}} \frac{p_{\mathrm{A}}}{p_{\mathrm{C}}} \ln \left(\frac{p_{\mathrm{C}}}{p_{\mathrm{A}}}\right)
$$

Writing $r=p_{\mathrm{C}} / p_{\mathrm{A}}$, the pressure ratio from A to $\mathrm{C}$,

$$
\rho g y_{\mathrm{A}}=\left(p_{\mathrm{C}}-p_{\mathrm{A}}\right)+x_{\mathrm{A}} p_{\mathrm{C}} \frac{1}{r} \ln r
$$

Equations (7) and (8) give the relation between $y_{\mathrm{A}}$ and $p_{\mathrm{A}}$. The first term on the right gives the well-known result for no aeration, while the second gives the effect of the air. The form of equation (8) is convenient because the value of $x_{\mathrm{A}}$ is likely to be fixed by the aerator and so known, and the absolute pressure $p_{\mathrm{C}}$, being close to atmospheric pressure, is approximately constant.

\subsection{Analysis of the whole siphon system, including losses}

To analyse the whole system, it suffices to apply Bernoulli's equation with loss terms to the flows up to $\mathrm{A}$ and from $\mathrm{C}$ onwards, which would be straightforward but that the flow is aerated beyond C. Because the flow is turning at $\mathrm{C}$ and the buoyancy force will then cease to oppose the flow, it is convenient to take the datum at the mid-depth of the downstream flow, distance $d$ below the downstream surface (although this means that $p_{\mathrm{C}}$ is not exactly atmospheric pressure).

In the following, the symbols $L_{\mathrm{A}}$ and $L_{\mathrm{C}}$ have been used to represent the losses from entry to $\mathrm{A}$ and from $\mathrm{C}$ to exit respectively, measured in numbers of dynamic heads of water. As noted earlier, the relatively small friction loss in the pumping section $\mathrm{AC}$ can be lumped part into $L_{\mathrm{A}}$ and part into $L_{\mathrm{C}}$ without introducing significant error. Thus, from the entry to A,

$$
p_{\mathrm{A}}+\frac{1}{2} \rho v^{2}+\rho g\left(y_{\mathrm{A}}-H-d\right)=p_{0}-L_{\mathrm{A}}\left(\frac{1}{2} \rho v^{2}\right)
$$

From $\mathrm{C}$ to the exit,

$$
p_{\mathrm{C}}=p_{0}+\rho g d-\frac{1}{2} \rho v^{2}+L_{\mathrm{C}}\left(\frac{1}{2} \rho v^{2}\right)
$$

The coefficient $L_{\mathrm{C}}$ includes both the energy loss at the exit and the loss in the diffuser $\mathrm{CD}$, together with any additional loss that may arise in the diffuser from the fact that the water is aerated.

Combining equations (8) to (10) and expressing the result in terms of head rather than pressure,

$$
H=\left(L_{\mathrm{A}}+L_{\mathrm{C}}\right) \frac{v^{2}}{2 g}+B
$$

where $B$ is the buoyancy head, given by

$$
B=x_{\mathrm{A}}\left(\frac{1}{r} \ln r\right) \frac{p_{\mathrm{C}}}{\rho g}
$$

Equation (11) shows clearly that the driving head $H$ is equal to the total of the flow losses and the buoyancy head. Increasing the aeration $x_{\mathrm{A}}$ increases the buoyancy term and so reduces $v$, giving the characteristic of the siphon. Conversely, reducing the overall loss coefficient causes $v$ to increase.

\subsection{Efficiency}

Regarding the siphon as an air pump, there are two categories of loss. One, comprising the inlet and exit losses plus the friction and bend losses, increases rapidly as the velocity of the water increases; this head loss is proportional to the square of the velocity of the water. The other, the loss due to the upward drift of the bubbles, reduces as the water velocity increases.

The first kind of loss appears in equation (11) as a head loss of $\left(L_{\mathrm{A}}+L_{\mathrm{C}}\right) v^{2} /(2 g)$. It is convenient to write this as $K v^{2} /(2 g), K$ being the overall loss coefficient. Since the available head of water is $H$, this loss is a fraction $K v^{2} /(2 g H)$ of the energy available from the water. The remaining head $H-K v^{2} /(2 g)$ is balanced by, and so equal to, the buoyancy head $B$ of the bubbles in the downward leg of the siphon.

The power loss per unit cross-sectional area due to drift of the bubbles is the product of the buoyancy pressure and the drift velocity, i.e. $\rho g\left[H-K v^{2} /(2 g)\right] s v$. Thus the fractional loss due to slip is $\left[1-K v^{2} /(2 g H)\right] s$, and the efficiency $\eta$ of the siphon as an air pump, i.e. the ratio of the output energy in the pumped air to the available input energy in the water, is given by

$$
\begin{aligned}
\eta & =1-\frac{K v^{2}}{2 g H}-\left(1-\frac{K v^{2}}{2 g H}\right) s \\
& =(1-s)\left(1-\frac{K v^{2}}{2 g H}\right)
\end{aligned}
$$

In this expression can be seen the contributions to the loss from drift of the bubbles (the term in the first pair of parentheses), and from friction and exit loss (the second pair of parentheses). It needs to be borne in mind that the 
slip ratio, $s$ is not a constant but varies with the velocity of the water.

\subsection{Optimum velocity of flow of the water}

In a siphon of given geometry, the water flow velocity can be adjusted to yield the highest efficiency, or the highest power, or some other condition. With the drift velocity $s v$ taken to be constant, it is readily shown by differentiating equation (13) with respect to $v$ and setting the result to zero that the efficiency is maximum when

$$
v^{2}\left(\frac{1}{s}-\frac{1}{2}\right)=\frac{g H}{K}
$$

This equation gives the water flow velocity for maximum efficiency as an air pump of a given siphon for which $s v$, $K$ and $H$ are known.

In practice, the maximum achievable power output may be of greater interest than the maximum efficiency. The power output per unit area of pipe cross-section, $P$, is given by the product of the buoyant pressure of the air and the air flow velocity. Thus

$$
P=\rho g\left(H-\frac{K v^{2}}{2 g}\right) v(1-s)
$$

Again by differentiating with respect to $v$, the condition for maximum power output is found:

$$
v^{2}(1.5-s)=\frac{g H}{K}
$$

Figure 2 shows curves for the water velocity $v$ against the ratio $(g H / K)^{1 / 2}$. Curves are shown for two conditions: for maximum efficiency, and for maximum power per unit area of cross-section, of the siphon as an air pump. The following calculation illustrates how these curves can be used in choosing the operating conditions of a given siphon.

\subsubsection{Sample calculation}

Consider the case of a weir and siphon for which the available water head $H$ is $1.2 \mathrm{~m}$, the overall loss coefficient $K$ is 0.7 and the drift speed of the bubbles, $s v$, is $0.25 \mathrm{~m} / \mathrm{s}$. (With careful design of the flow passages and of the exit diffuser to minimize losses, it should be possible to achieve an overall loss coefficient of 0.7 or lower.)

The value of $(g H / K)^{1 / 2}$ is $4.10 \mathrm{~m} / \mathrm{s}$. From Fig. 2, it is found that the maximum efficiency of the siphon as an air pump is achieved when the water flow speed $v$ is $1.66 \mathrm{~m} / \mathrm{s}$.

Then $s=0.15$; from equation (13), the efficiency is 0.78 . The power output, given by $\eta \rho g H v$, is $15.2 \mathrm{~kW}$, and the losses are $1.6 \mathrm{~kW}$ friction, inlet and exit loss and $2.7 \mathrm{~kW}$ loss due to drift of the bubbles. All powers are expressed per square metre of pipe cross-section.

If the maximum power output is sought, Fig. 2 shows that the required water flow speed $v$ is $3.43 \mathrm{~m} / \mathrm{s}$. Then the power output of the siphon as an air pump is $24.3 \mathrm{~kW}$ per square metre of pipe cross-section. The losses amount to $1.9 \mathrm{~kW}$ drift loss, and $14.1 \mathrm{~kW}$ friction and exit loss, both per square metre of pipe cross-section. The efficiency is 0.60 . In practice, a water speed intermediate between these two values is needed to optimize the cost of power.

\subsection{Aerator height}

Continuing with the example from the previous section, let us select the water velocity $v=2.30 \mathrm{~m} / \mathrm{s}$, which is intermediate between the values for maximum efficiency and maximum power. The head loss $K v^{2} /(2 g)$ is then $0.19 \mathrm{~m}$; therefore the buoyancy head $B$ is $1.01 \mathrm{~m}$.

As noted in Section 2, the maximum void fraction at which bubbly flow can be maintained is $\alpha=0.3$. This corresponds to $x=0.3 / 0.7=0.429$, since $x$ is the volumetric ratio of air to water while $\alpha$ is the ratio of air to the total volume. To allow a margin of safety, a smaller value of $x$, say, 0.35 , corresponding to $\alpha=0.26$, is taken.

The pressure $p_{\mathrm{C}}$ is approximately atmospheric, say $100 \mathrm{kN} / \mathrm{m}^{2}$. Using equation (12),

$$
\frac{1}{r} \ln r=0.283
$$

and hence

$$
r=\frac{p_{\mathrm{C}}}{p_{\mathrm{A}}}=1.555
$$

Finally, using these results in equation (8), the height of the aerator is obtained as $y_{\mathrm{A}}=4.65 \mathrm{~m}$, this being the height above the point $\mathrm{C}$ at the exit from the downward leg of the siphon. If the exit point $\mathrm{C}$ is taken to be a distance $d=0.3 \mathrm{~m}$ below the level of the water surface, then above the downstream water level the height is $0.3 \mathrm{~m}$ less than this, $4.35 \mathrm{~m}$. Above the upstream level the height is $3.15 \mathrm{~m}$.

\section{RANGE OF APPLICATION OF THE SIPHON HYDRO PLANT}

\subsection{Simple siphon}

In the siphon plant described, the head $H$ of water at the weir is opposed by the buoyancy head of the air bubbles and by losses, including the inlet and exit losses. Equation (11) sets this out in mathematical terms. For 


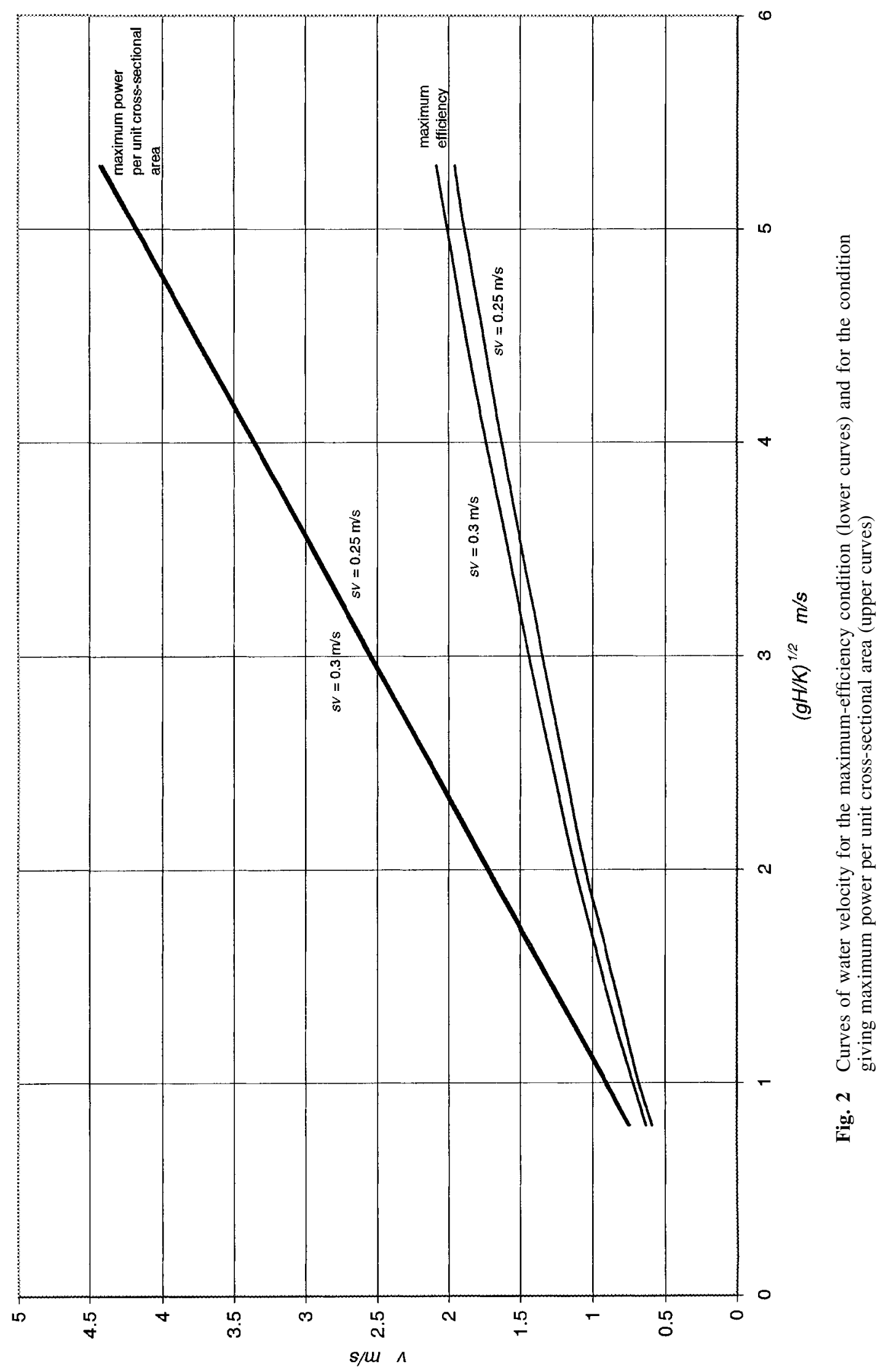


good efficiency, the buoyancy term should be large relative to the losses. (In the example shown in Subsection 3.4.1 and Section 3.5 above, when operating at maximum efficiency the buoyancy head $B$ is $1.06 \mathrm{~m}$, and the head corresponding to the friction and exit losses is $0.14 \mathrm{~m}$. It is of interest that, even if the loss coefficient is doubled to $K=1.4$, at maximum efficiency the buoyancy head is almost unchanged: $1.08 \mathrm{~m}$.)

There is a limit to the buoyancy head $B$. (This limit does not apply in the case of the hydraulic compressor, in which atmospheric pressure is at the inlet to the column, and not at the bottom.) The pressure $p_{\mathrm{C}}$ is close to atmospheric, and $x_{\mathrm{A}}$, the volumetric ratio of air to water at the aerator, has a maximum practical value of about 0.35 . In equation (12), the factor

$$
\frac{1}{r} \ln r
$$

has a maximum value $e^{-1}$, or 0.368 , which occurs when $r=e$.

Taking these values with $p_{\mathrm{C}}=100 \mathrm{kN} / \mathrm{m}^{2}$, it is found that the maximum possible value of $B$ is $1.31 \mathrm{~m}$. For an air-pumping efficiency of 70 per cent or more, this limits the driving head at the weir, $H$, to about $1.7 \mathrm{~m}$ at the most. This value for $H$ can be increased if a lower efficiency is acceptable, or if a greater value of $x_{\mathrm{A}}$ can be achieved. However, $x_{\mathrm{A}}$ is unlikely to be capable of very much improvement; therefore, as weir heights rise beyond about $1.7 \mathrm{~m}$ a single-stage siphon must inevitably become less and less efficient.

\subsection{Two-stage siphon}

The range of operation of the siphon can be extended by introducing air into the descending water column $\mathrm{AC}$ at more than one point in its length. As the water-air mixture descends from $\mathrm{A}$, the pressure increases and the volume of the air decreases; it is then possible to introduce further air. It is theoretically possible to do this at any number of points, successive points being at gradually higher pressures. In practice it is unlikely that more than two aeration points would be used in the descending column because of the complexity introduced. In cases where the water head at the weir is greater than about $2 \mathrm{~m}$, rather than using two-stage siphons, it would seem better to use an intermediate side pond, extracting the energy from the water with two successive siphon systems.

\section{PRACTICAL ISSUES}

\subsection{Ice formation and trash}

Because of the drop in temperature through the turbine, under a variety of conditions, ice will appear in the air in a form like powder snow. The general effect of moist air is beneficial, since it improves the turbine efficiency due to reheat from the condensation. Ice is only likely to be troublesome in some parts of the manifolding, where it may prove necessary to adopt electrical heating. However, this is likely to cost less than the benefits of reheat; therefore, surprisingly, the formation of ice is expected to improve performance overall.

Any trash that enters the siphon may lodge on aerators, etc., and thus trash screens are desirable. However, in this system, trash is unlikely to cause damage, as it may in water turbines.

\subsection{Turbine types and matching}

Radial air turbines, made in large numbers by turbocharger manufacturers, are the obvious choice for early development, even though slightly better efficiencies are to be had with axial flow turbines. Operating at ambient temperatures and below, the turbines can be made in less specialized materials than those of turbochargers, which have to withstand engine exhaust temperatures. Turbine efficiencies of 80-85 per cent should be readily achievable.

With variable water flowrates in rivers, steps have to be taken to match the siphon and turbine plant to the available water flow. On large rivers this can be accommodated by switching units in and out; as many as forty siphons and four turbines at weirs in some locations may be needed. With reduced flow in such a case, one or two siphons per turbine would be emptied, until one turbine needed to be shut down, and so on.

\subsection{Costs}

The capital cost of the siphon type of hydro plant per installed kilowatt is expected to be attractively low compared with an equivalent plant based on water turbines, owing to the small size of the machinery, its convenient location above water level and the simplicity of the civil engineering work. The costs are especially low where an existing weir can be utilized but, even when a new weir has to be built, the capital cost is still likely to be lower than other forms of hydro plant.

The overall efficiency of the plant, while less than that of conventional hydro plant, should be at least 60 per cent. Unless there is a water shortage, when efficiency may become very important, the low first cost and capital charges of the siphon plant should make it very competitive in the low-head hydro market.

\section{CONCLUSIONS}

The hydropower system based on pressure-exchanging 
siphons offers the prospect of harnessing power economically from the large number of potential low-head hydro sites which are not viable using water turbines. Airpumping efficiencies of 70 per cent or better should be achievable; overall efficiency should be better than 60 per cent. Although such values of efficiency are lower than usually found in hydro plant, siphon installations should be economically attractive owing to the relatively low capital cost of the system.

In single-stage form the system is suitable for heads up to about $1.7 \mathrm{~m}$. For higher heads, the system can be used in two or more stages, either by introducing air into the descending water column at more than one point or by using intermediate side ponds.

\section{REFERENCES}

1 Moreira, J. R. and Poole, J. R. Hydropower and its constraints. In Renewable Energy Sources for Fuels and Electricity (Eds T. B. Johansson, H. Kelly, A. K. N. Reddy and R. H. Williams), 1993 (Earthscan Publications, London).

2 French, M. J. Design methods applied to wave energy converters. In Proceedings of the International Conference on Engineering Design (ICED 91), Zurich, 1991, pp. 139145.

3 Wilson, E. M., Bassett, D. E. and Jones, I. D. Two new machines for hydraulic power from low heads. In IAHR Symposium on Hydraulic Machinery in the Energy Related Industries, Stirling, August 1984.

4 Bellamy, N. W. Low head hydroelectric power using pneumatic conversion. Instn Electl Engrs Power Engng J., May 1989, 3, 109-113.

5 Anon. A large hydraulic air compressing plant. Engineer, 10 November 1911, 112, 482-484.

6 Hartenberg, R. S. and Denavit, J. The fabulous air compressor. Mach. Des., 21 July 1960, 32(15), 168-170.

7 Rice, W. Performance of hydraulic gas compressors. Trans. ASME, J. Fluids Engng, 1976, 96, 645-653.

8 Berghmans, J. A. and Ahrens, F. W. Performance of a hydraulic air compressor for use in compressed air energy storage power systems. Trans. ASME, J. Fluids Engng Advd Energy Systems, 1978, 213-227.

9 Ayers, D. L. Efficient hydraulic air compression for baseloaded combustion turbines. In Proceedings of the American Power Conference, 1991, pp. 406-412.

10 Bidini, C., Grimaldi, C. N. and Postrioti, L. Performance analysis of a hydraulic air compressor. Proc. Instn Mech. Engrs, Part A, Journal of Power and Energy, 1999, 213, 191-203.

11 Bellamy, N. W. The Syfogen low head pneumatic hydroelectric system. In Proceedings of the Conference on Hydropower into the Next Century, Barcelona, Spain, 1995, pp. 563-570.

12 Wallis, G. B. One-dimensional Two-phase Flow, 1969 (McGraw-Hill, New York).

13 Soo, S. L. Multiphase Fluid Dynamics, 1990 (Science Press, Beijing). 